\title{
THE DEVELOPMENT OF RIA IN THE EUROPEAN UNION: AN OVERVIEW
}

\author{
ANDREA RENDA
}

\begin{abstract}
The European Commission has successfully managed to adopt and implement ex ante impact assessment procedures since 2003, and available data show that the IA documented are of increasingly good quality. Even though margins for improving the European Commission IA system persist, other EU institutions and almost all $E U$ member states significantly lag behind in terms of IA implementation. The experience of past research projects, including the European Network for Better Regulation and the recent OECD EU15 project confirmed that at national level IA features a high adoption-implementation gap. This paper draws on EU and international experience to draw some recommendations, which include the need for more sophisticated legal and economic analysis in RIA, to make it a more credible instrument for ex ante policy appraisal; and the need for gradually introduced, carefully designed RIA system which take advantage of the enormous success obtained by other, simpler models, such as the Standard Cost Model for the measurement and reduction of administrative burdens.
\end{abstract}




\title{
THE DEVELOPMENT OF RIA IN THE EUROPEAN UNION: AN OVERVIEW
}

\author{
ANDREA RENDA
}

\section{TABLE OF CONTENTS}

INTRODUCTION: A CONSTANTLY EVOLVING LANDSCAPE .3

1 IMPACT ASSESSMENT IN THE EUROPEAN UNION:

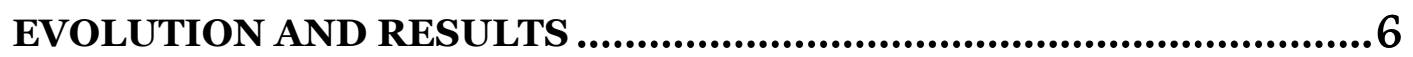

1.1 Impact assessment in the EU: a brief account ............................6

1.2 Impact assessment in the EU: a look at the evidence ...................9

1.2.1 The European Commission: progress achieved and margins for improvement ................................................................ 9

1.2.2 Other EU institutions................................................................... 13

1.3 The future of EU impact assessment ........................................... 13

1.4 The EU impact assessment system: lessons learned.................... 14

2 RIA IN EUROPEAN COUNTRIES: EMERGING TRENDS ................ 16

2.1 Grouping EU countries ..................................................... 18

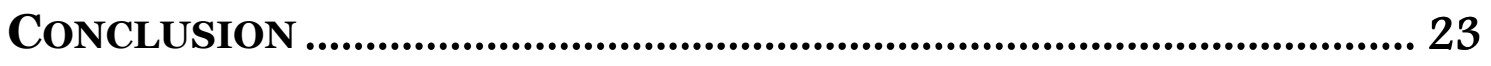

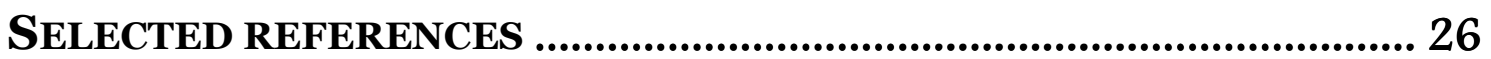




\title{
THE DEVELOPMENT OF RIA IN EUROPEAN COUNTRIES: AN OVERVIEW
}

\author{
ANDREA RENDA ${ }^{1}$
}

\section{INTRODUCTION: A CONSTANTLY EVOLVING LANDSCAPE}

$\mathrm{R}$ egulatory Impact Assessment (RIA) is considered as one of the most useful tools for the scrutiny of the flow of regulation, as well as a the word feature the world feature some form of RIA, which takes various forms and serves different purposes depending on the context in which the procedure is introduced. Compared with other tools such as the measurement of administrative burdens, the introduction of consultation procedure or the practice of ex post monitoring and evaluation, RIA appears to require a more profound change in the culture of public administrations and bureaucrats, and has therefore encountered significant problems in its implementation around the world. From an international perspective, the first countries that managed to mainstream RIA into their policymaking process were notably common law countries, especially within the broader context of public management reforms - e.g. the New Public Management wave in the UK, the Reinventing Government in the United States ${ }^{2}$. Other countries, in particular civil law countries, have committed resources to the development of ex ante RIA practices, but for many years have failed to fully implement RIA for a substantial part of their flow of legislation. Accordingly, a conspicuous adoption-implementation gap has emerged, as observed by several scholars in the past few years 3 .

Against this background, the international RIA landscape appears more like a patchwork of very different experiences and alternate fortunes, rather than a consistent and parallel development. One scholar has compared the practice of comparing RIA systems around the world to that of comparing apples and pears, given the existing divergence in the way national governments have attempted to mainstream this procedure in their policymaking process 4 .

More in detail, RIA systems differ according to a number of characteristics, including the following:

- Scope. Some countries have introduced mandatory RIA only for secondary legislation (e.g. the United States), whereas other legal systems require it

1 Senior Research Fellow, Head of Regulatory Affairs, Centre for European Policy Studies, Brussels (Belgium); Professor of Antitrust and Regulation, LUISS Guido Carli, Rome (Italy).

${ }^{2}$ Renda (2006)

3 Radaelli

4 Radaelli 
also for primary legislation or even for non-binding policy documents (e.g. the European Union). Some countries limit RIA to certain sectors (e.g. network industries, or proposals to implement EU legislation), whereas others apply them to all the new legal proposals. Some countries have enacted thresholds to select the proposals that should undergo RIA (e.g., the US, the UK), whereas in other systems there is no such threshold, and the selection follows other principles, including that of proportionate analysis (e.g. the EU).

- Purpose. In some countries RIA serves the main purpose of enabling the monitoring of the performance of bureaucrats, within a principal-agent scheme between the government and its administration (e.g. the United States). To the contrary, in other legal systems the main purpose has been in-house learning (the EU), or specific targets to contrast poverty (Ireland), reduce administrative burdens (the Netherlands, Germany), allow for dialogue with the business sector (Sweden) or even the reduction of corruption through greater transparency and accountability (as in several developing countries).

- Methodology and quantification. Different scopes and different purposes are also reflected in a different emphasis being placed on the quantification and monetization of impacts in different countries. Eastern European countries, such as Poland and in particular Ukraine, have traditionally placed more emphasis on RIA as an explanatory document, and as such have made limited use of quantitative cost-benefit analysis in their RIA documents; on the other hand, the United States have devoted growing efforts to the monetization of impacts, including non-market goods such as biodiversity or the value of human lives, in order to increase the transparency of decision-making and the measurability of impacts over time. Also the European Commission has strengthened the emphasis on quantitative analysis since 2005, and later with the appointment of the Impact Assessment Board.

- Governance and oversight. In several countries there is a single, dedicated unit nested in the centre of government, with the role of consultant, advisor and/or adversarial gatekeeper for the departments, ministries or other bodies in charge of drafting the RIA document. In some countries the whole RIA process is managed by the Cabinet Office (e.g., the UK, Italy), in others by the Ministry of Economy or Finance (e.g., the Netherlands, Slovakia), in others by the Ministry of Justice (e.g., Hungary) or the Ministry of Interior (the Czech Republic), depending on the purpose and scope of the RIA system. In addition, some countries have appointed ad hoc external oversight bodies in charge of monitoring the RIA activity performed by the government: in most cases these bodies - such as Actal in the Netherlands, the Normenkontrollrat in Germany or the Regulatory Policy Commission in the United Kingdom - have a more specific mandate confined to the measurement of administrative burdens or the compliance costs of legislation. Finally, in some countries other bodies, such as courts of auditors, perform an ex post oversight function (e.g. the NAO in the UK, the GAO in the US, the Dutch Court of Audit, the European Court of Auditors, etc.). 
- Effective implementation. Past research projects such as the European Network for Better Regulation (ENBR) have shown that, despite a general trend towards the adoption of the RIA system, only a fistful of European countries have effectively reached a significant number of RIAs published (see Section 3 below). Cases in which RIA has emerged as a key step in the policy process include to some extent the United Kingdom and non-EU countries such as Ukraine. In all other countries, the situation was less encouraging, although the past 2-3 years have shown some sign of development in countries like Sweden, Ireland, the Netherlands and, most recently, France.

This short paper draws on the experience of the DIADEM database within ENBR and also on similar research projects (including EVIA, the SSIA project for the European Commission DG EMPL, the IA-TOOLS project of the European Commission's Joint Research Centre, etc.) to describe the current trends in the adoption and implementation of RIA in European countries and beyond. In particular, Section 1 below provides a description of the EU impact assessment experience and illustrates data on the 475 IAs completed by the European Commission between 2003 and end 2009. Section 2 looks at the characteristics of RIA in the EU27, and focuses on specific trends emerged in the past few years, such as the need for centralized oversight, the focus on administrative and compliance costs, the refinement of methodological guidance, the completion of the policy cycle with monitoring and ex post evaluation, and appointment of external oversight bodies in charge of overseeing the governmental RIA activity. Section 3 concludes by offering some thoughts on the current state of the debate on RIA, including the oft-neglected problem of how to improve the methodological approach to ex ante policy appraisal. 


\section{IMPACT ASSESSMENT IN THE EUROPEAN UNION: EVOLUTION AND RESULTS}

\subsection{Impact assessment in the EU: a brief account}

The EU experience in regulatory impact assessment began in 1986, when the UK took its turn in the Presidency of the Council. For this reason, the impact analysis procedure introduced - called Business Impact Assessment (BIA) closely echoed the UK model of Compliance Cost Assessment. 5 The BIA system was subject to heavy critiques, mostly related to its incompleteness and uncertain institutional setting. This led the Commission to issue in $2001 \mathrm{a}$ White Paper on European Governance and the Lisbon Council to mandate the creation of a high-level advisory group (the 'Mandelkern Group') for the drafting of an "action plan for better regulation" and the definition of a new model of impact assessment to be implemented at Community level. The Mandelkern Group was created to "set out by 2001 a strategy for further coordinated action to simplify the regulatory environment, including the performance of public administration, at both national and Community level", and after the Ministers for Public Administration from EU members states had signed the Strasbourg Resolution in November 2000, mandating the advisory group to "develop a coherent approach to this topic and to submit proposals to the Ministers, including the definition of a common method of evaluating the quality of regulation."

The Commission's 2001 White Paper on European Governance clarified the Commission's agenda for the establishment of new better regulation standards in the EU. ${ }^{6}$ The preparatory report of the working group on evaluation and policy recommended the use of cost-benefit analysis as the most complete and accurate methodology in the evaluation of proposed legislations.7 However, exact economic calculations were considered not to be the most important contributors to regulatory quality. Rather, the working group took a 'lessondrawing' approach by stating that observing the international experience and undertaking contextualised benchmarking are the most important steps towards a compete understanding of the logic of decision-making. The working group also suggested that monitoring existing EU legislation was at least as important as evaluating the expected impact of new regulation. ${ }^{8}$

A few months after the publication of the White Paper on European Governance, the Mandelkern Group on Better Regulation published its final report. The report, still considered as one of the key reference on RIA at the international level - specified some of the features of the prospective new RIA

\footnotetext{
5 See Section 1.2.1 below.

${ }^{6}$ See European Commission, White Paper on European Governance, COM(2001)727, 25 July 2001.
}

7 See Preparatory Work for the White Paper, op. cit., Section 3.2.1, p. 91.

8 Ibid., Section 3.3.3, p. 92. 
model, suggesting its adoption by the Commission before June 2002 and its application to all Commission proposals with possible regulatory effects. 9 The Mandelkern Report contained a set of recommendations for an effective implementation of such procedure. The Mandelkern Group also recommended the adoption of a 'dual stage' RIA model, with a preliminary impact assessment devoted to the analysis of alternative regulatory options and an extended impact assessment in which the detailed assessment of the benefits and costs of the preferred regulatory option is performed. After a specific call for action issued by the European Council meetings of Göteborg and Laeken, the Commission announced its Action Plan for Better Regulation in June 2002. The new impact assessment model was introduced as part of this wider Action Plan, together with a communication aimed at simplifying and improving the regulatory environment and measures aimed at promoting "a culture of dialogue and participation" within the EU legislative process. ${ }^{10}$

The new integrated impact assessment (IIA) model introduced in 2002 - which incorporates not only the economic impact, but also the social and environmental impact of the proposals concerned - adopted initially a 'dual stage' approach. All Commission initiatives proposed for inclusion in the Annual Policy Strategy or the Commission Legislative and Work Programme and requiring some regulatory measure for their implementation - thus including not only regulations and directives, but also White Papers, expenditure programmes and negotiating guidelines for the international agreements - must undergo a 'preliminary impact assessment'. ${ }^{11}$ Moreover, a selected number of proposals with large expected impact, are subjected to a more in-depth analysis called 'extended impact assessment'.

The Commission assessed the first results of its new Integrated Impact Assessment model in December 2004, by drawing a mixed picture on the progress made in improving the quality of EU legislation. A first measure was to request services to establish 'Roadmaps' for the initiatives they have put forward

9 Mandelkern Group, Final Report (available at http://europa.eu.int/comm/ secretariat_general/impact/docs/mandelkern.pdf - visited 2 August 2005).

${ }_{10}$ During 2002 and early in 2003, the Commission developed its Action Plan through eight targeted Communications, at the same time defining with the European Parliament and the Council an overall strategy on better law-making. The Communications addressed the following issues: 1) General principles and minimum standards for consultation $(\mathrm{COM}(2002) 704) ; 2)$ the collection and use of expertise (COM(2002) 713); 3) impact assessment (COM(2002) 276), including internal Guidelines; 4) Simplifying and improving the regulatory environment $(\mathrm{COM}(2002) 278) ; 5)$ proposal for a new comitology decision (COM(2002) 719); 6) operating framework for the European Regulatory Agencies (COM(2002) 718); 7) framework for target-based tripartite contracts (COM(2002) 709); and 8) Better monitoring of the application of community law (COM(2002) 725).

${ }_{11}$ Proposals that are exempted from impact assessment include: a) Green Papers where the policy formulation is still in process; b) periodic Commission decisions and reports; c) proposals following international obligations; d) executive decisions, such as "implementing decisions, statutory decisions and technical updates, including adaptations to technical progress"; and e) Commission measures deriving from its powers of controlling the correct implementation of Community Law (although the Commission may in some instances decide to carry out an impact assessment). See Communication on impact assessment, $\operatorname{COM(2002)}$ 276, 5 June 2002, Section 2 ("Coverage"). 
for inclusion in the Annual Policy Strategy (APS) and in the Commission's Work Programme. ${ }^{12}$ But several sources of pressure were calling for some major effort from the Commission in order to significantly improve the momentum of better regulation efforts, with specific emphasis on strengthening and improving impact assessment methods.

The Commission took action in March 2005 with a new Communication on Better Regulation for Growth and Jobs in the European Union, defining the achievements of the first years of implementation of the IIA as "first steps in what must be a permanent effort". 13 Recent major steps in the Commission's better regulation agenda include the following:

- Since 2005, the re-launch of the Lisbon agenda under the name "Partnership for growth and jobs" has identified better regulation as one of the main pillars of competitiveness and sustainable development in Europe ${ }^{14}$. The dual-stage IIA system was replaced by a single document (IA), and the depth of analysis relies on the application of the principle of proportionate analysis (see box 1 below).

- The European Parliament and the Council have been increasingly involved in the better regulation agenda, a tendency which culminated in the 2003 Inter-Institutional Agreement on Better Lawmaking and the 2005 agreement on a "common approach" to impact assessment 15 .

- In late 2006, the Commission appointed an Impact Assessment Board (IAB), responding to repeated calls for better quality assurance mechanisms and stronger coordination in the ex ante assessment activities carried out by the various DGs ${ }^{16}$.

- In January 2007, the Commission launched its Action Programme for the measurement and reduction of administrative burdens generated by EU legislation ${ }^{17}$.

- The Commission reviewed its minimum standards for external consultation in 2007. It confirmed the current rules and decided to apply them more effectively by improving feedback, ensuring plurality of views, etc. The newly appointed IAB must check that these standards are correctly applied.

- The Commission gradually strengthened its Simplification Rolling Programme, which covers 164 measures for 2005-2009 and is now part of the annual work programme. The Commission has already proposed or

\footnotetext{
${ }^{12}$ See European Commission Staff Working Paper, Impact Assessment: Next Steps, cit.

${ }^{13}$ See the Communication on Better Regulation for Growth and Jobs, op. cit., note 172.

${ }_{14} \mathrm{See} \operatorname{COM}(2005) 24$, at \$3.2.3.

15 Both documents can be found at http://ec.europa.eu/governance/ better_regulation/ ii_coord_en.htm.

${ }^{16}$ For a short description of the IAB, see http://ec.europa.eu/governance/impact/ iab_en.htm.

17 COM(2007)23 final, 24 January 2007.
} 
adopted 91 such measures, and envisages the adoption of 44 new measures in $2008^{18}$.

- An ex post evaluation of the Commission's IA system was completed in April 2007, with overall mixed results and a number of suggestions for improving the system in the future ${ }^{19}$.

- A consultation on the future of the smart regulation agenda in the EU was launched in 2010, with a view to collecting stakeholder views on how to improve the system in the years to come.

Today, the Commission IA system is firmly nested into the Commission's policy cycle. The second Barroso Commission has so far placed emphasis on the need to perform ex post evaluation before any new IA is undertaken (which reinforces the analysis of the status quo and calls for the completion of the policy cycle). The IA procedure, coupled with stakeholder consultation, takes approximately 52 weeks to be completed, before the Commission proposal can indeed be finalized and sent - where appropriate - to other EU institutions. Figure 1 below shows the Commission policy process and the corresponding timing of IA.

Figure 1 - The European Commission's policy process

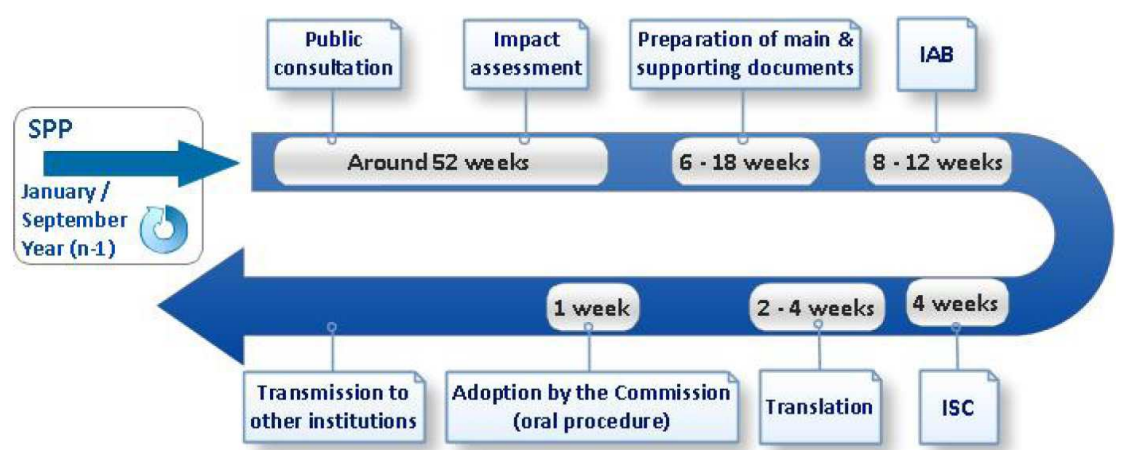

Source: European Commission, Impact Assessment Guidelines, 15 January 2009

\subsection{Impact assessment in the EU: a look at the evidence}

\subsubsection{The European Commission: progress achieved and margins for improvement}

The European Commission has certainly achieved important results in mainstreaming IA in its policymaking process, though important margins for improvement remain. At the end of 2009, the European Commission had completed 475 IAs, distributed as in Figure 2 below.

\footnotetext{
${ }^{18}$ See the Commission Communication on the Second Strategic Review of Better Regulation in the European Union, $\operatorname{COM}(2008) 32$, 30 January 2008.

19 See the main report at http://ec.europa.eu/governance/impact/docs/key_docs/ tep_eias_final_report.pdf.
} 


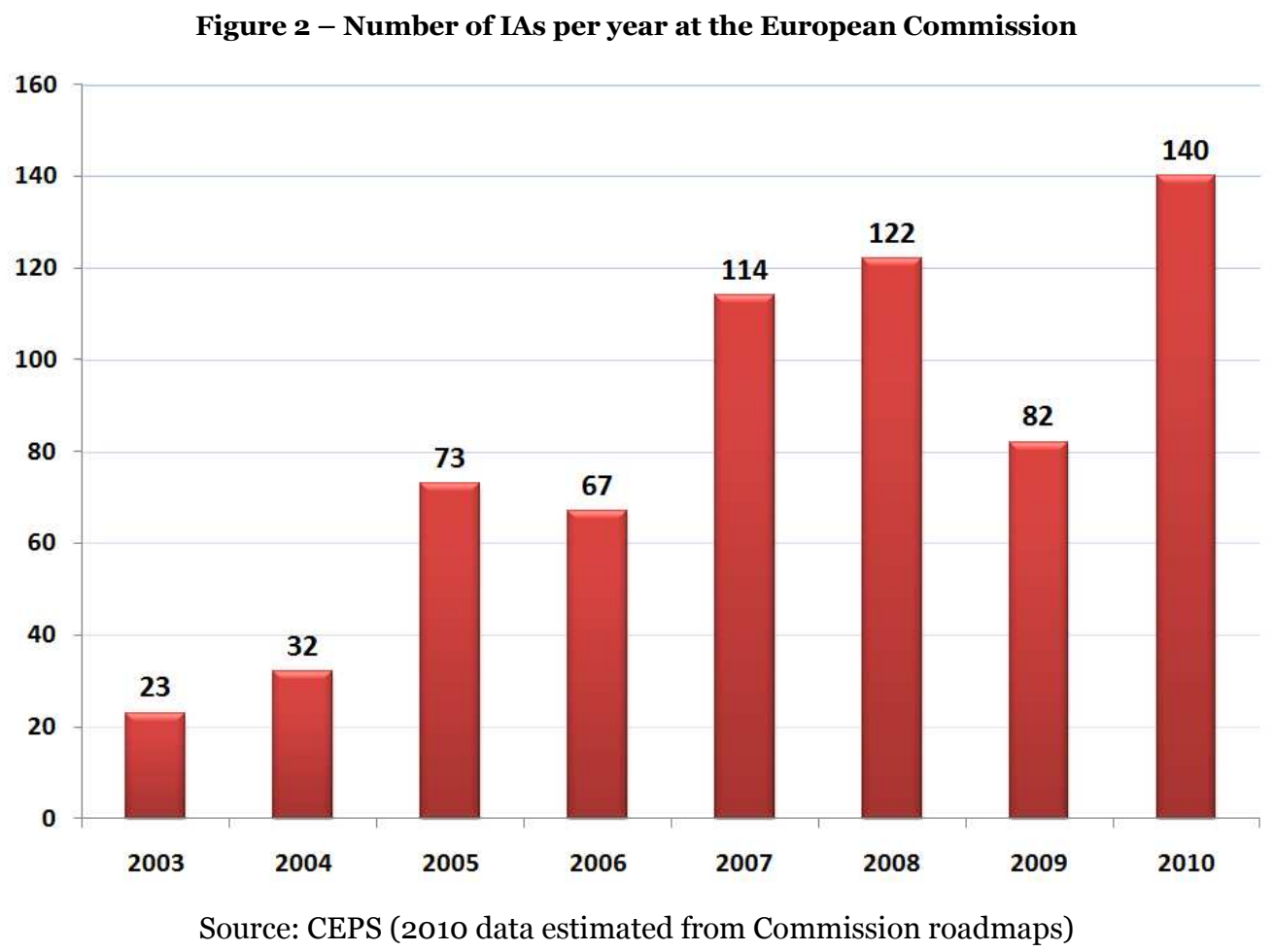

The number of IAs has been increasing significantly since 2006, although 2009 marked a slow-down due mostly to the transition towards a new European Commission and a new European Parliament. In 2010, at least 140 IAs are expected according to the available 2010 roadmaps ${ }^{20}$.

However, not all Commission DGs have been involved in the process in the same way. Figure 3 below shows that some DGs - i.e. Transport and Energy (TREN), Environment (ENV), Justice Liberty and Security (JLS), Enterprise and Industry (ENTR) and Internal Market (MARKT) - completed more than $60 \%$ of all Commission IAs, and other DGs only performed a few IAs over the 2003-2009 timeframe.

${ }^{20}$ See http://ec.europa.eu/governance/impact/planned_ia/roadmaps_2010_en.htm. 
Figure 3 - Number of IAs per DG, at December 2009

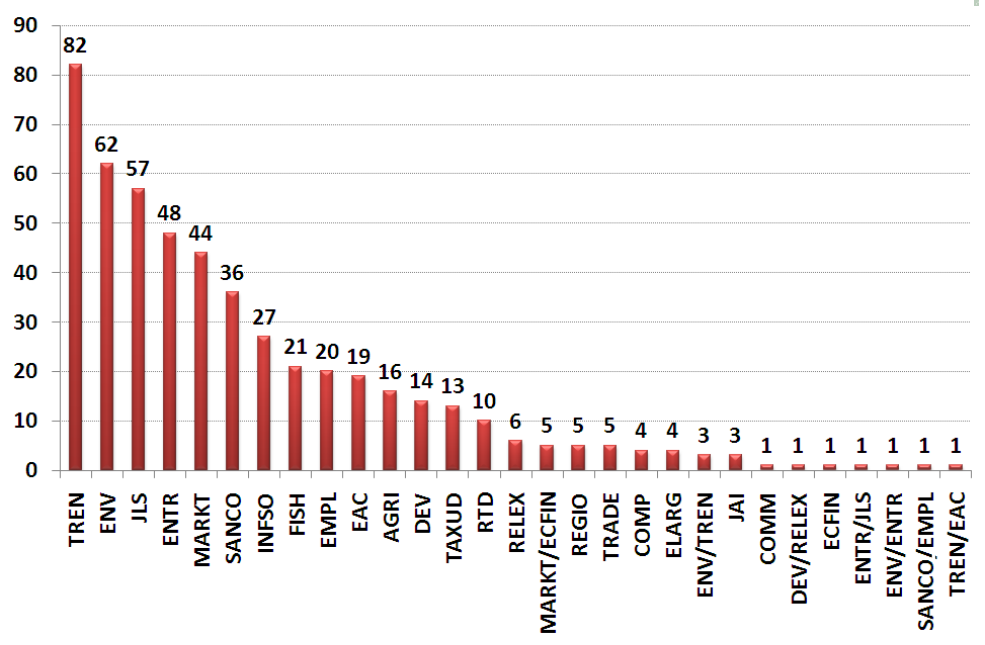

In any event, available data confirm that the Commission IAs have become more complete and transparent over time. In particular:

- The assessment (qualitative or quantitative) of economic, social and environmental impacts has become more systematic. Figure 4 below shows that in 2005, less than $30 \%$ of the IAs assessed the environmental impact, whereas economic and social impacts were considered in less than $70 \%$ of the IAs. In 2009, environmental impacts were assessed in 60\% of the IAs and economic and social impacts were assessed in almost all IAs.

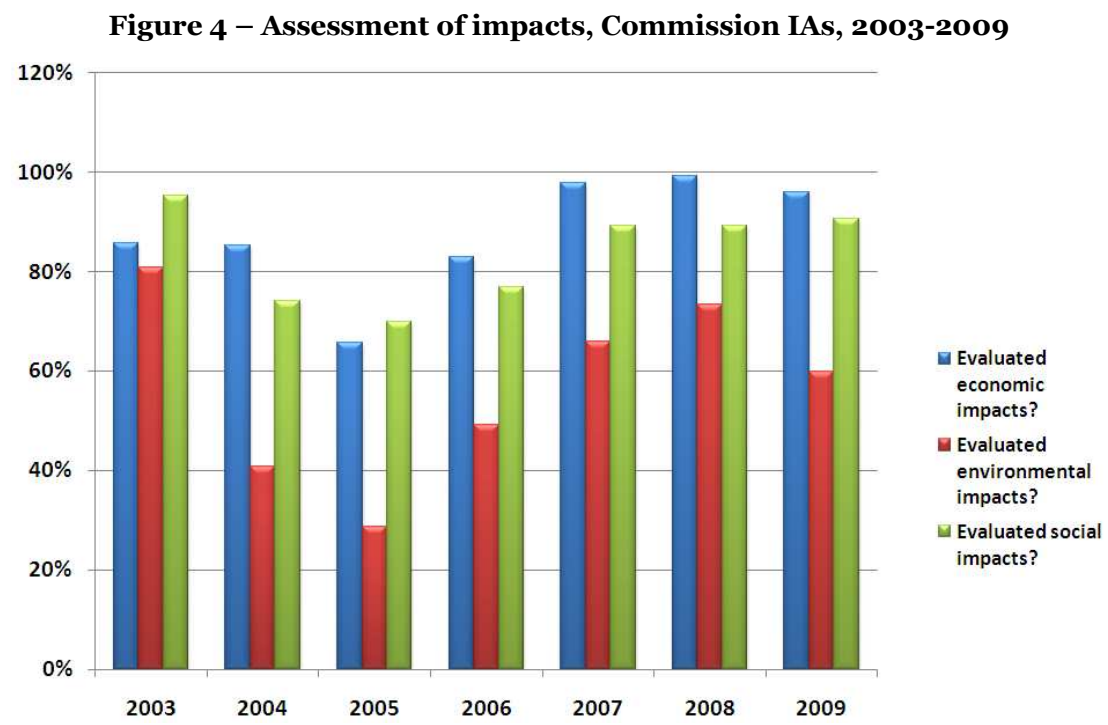

- The assessment of alternatives has become more systematic. As shown in figure 5 below, the costs and benefits of alternative policy options are more frequently quantified and monetized in Commission IAs, especially compared to the 2004-2005 period, in which the assessment of alternatives was very limited. Today, in approximately 30\% of the cases the European 
Commission provides an indication of the net benefits or cost-effectiveness of the policy options considered - a figure that must be appraised also in light of the fact that not all Commission IAs are related to binding policy actions.

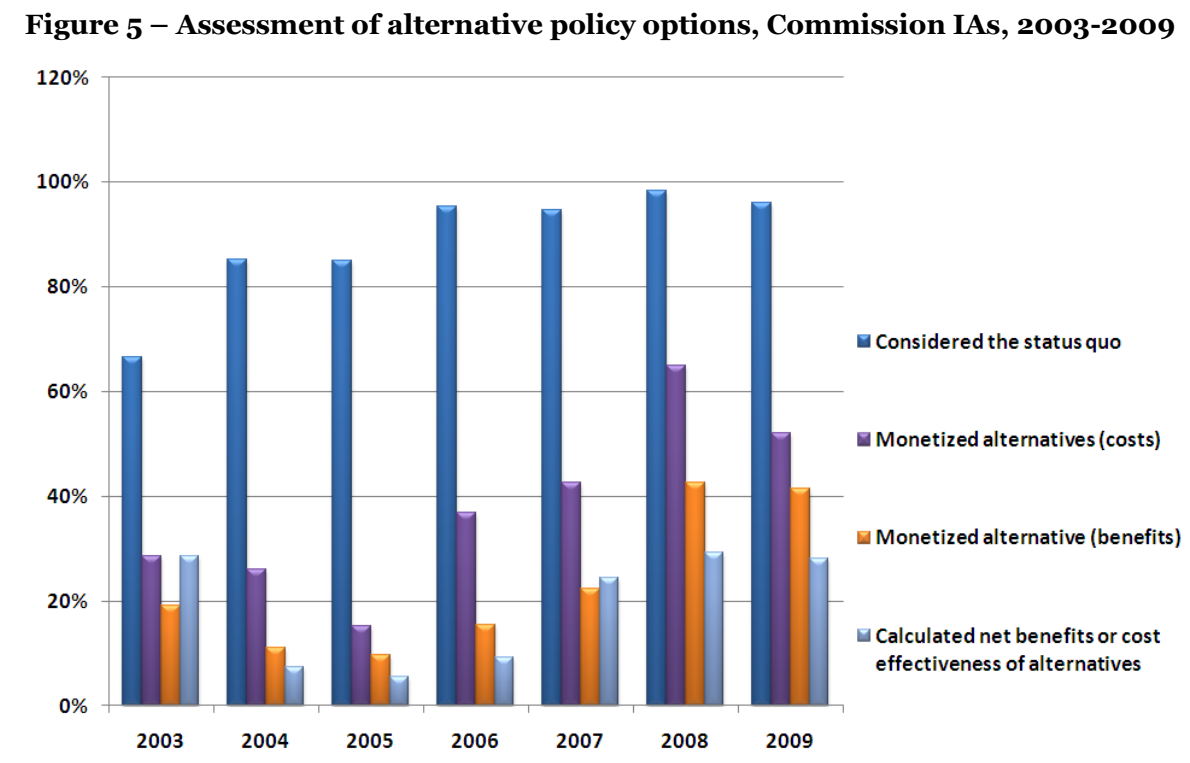

- The degree of sophistication of Commission IAs is on the increase. The number of IAs that embarked in difficult economic analyses such as the calculation of the number of lives saved by a given policy option is increasing year on year. At the same time, the Commission makes more use of discount rates when assessing future impacts; performs risk assessment more often; and offers a sensitivity analysis to check the robustness of its assumptions.

Figure 6 - Sophistication of Commission IAs, 2003-2009 (selected indicators)

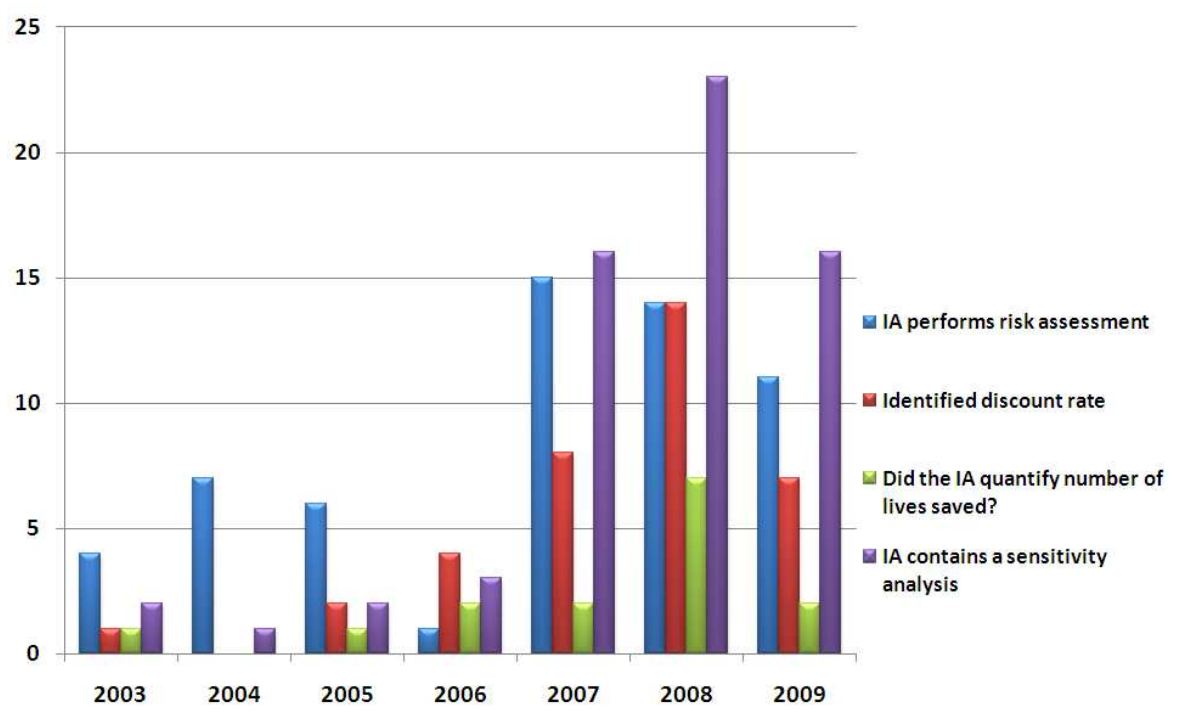




\subsubsection{Other EU institutions}

While the European Commission has managed to make systematic use of IA tools, it is no mystery that other EU institutions such as the European Parliament and the Council have largely failed to achieve the objective of performing assessments on their major amendments on Commission's proposals, despite their commitments expressed in the 2003 "InterInstitutional agreement on better lawmaking", and in the 2005 "Common Approach to Impact Assessment". This also means that European Commission IAs, once the proposal is amended during the co-decision procedure, lose their representativeness and their usefulness for potential users such as national governments.

More in detail, the European Parliament has gradually replaced the practice of IA with the commissioning of external background studies and briefing notes, which normally are not linked with the original Commission IA, and do not feature the structure of an IA document. The Council is reportedly making more use of Commission IAs, but after a pilot project on a limited number of amendments back in 2004, has dropped completely the production of IAs.

In a recent publication, Renda et al. (2009) debate whether the failure of the Common Approach to IA should lead to a new approach to inter-institutional dialogue at the EU level. Below, we briefly discuss this issue together with the other emerging trends in EU impact assessment.

\subsection{The future of EU impact assessment}

The EU experience with IA is considered as being fairly successful, but margins for improvement certainly exist. As confirmed also by the 70 opinions gathered by the Commission during the consultation on the future of smart regulation that ran between 23 April and 25 June 2010, the issues to be tackled in the years to come include the following ${ }^{21}$.

- First of all, many arguments seem to point at the need for an expanded role of the European Commission in performing IA throughout the policy cycle, including the co-decision procedure: these include the (current) failure of the Common Approach, the need to strengthen the commitment of EU institutions towards evidence-based policymaking, the need to provide an interface between EU and national levels, the economies of scale the Commission can reach in performing IA, and the need to ensure that administrative burdens are measured for each and every new piece of EU legislation (in its definitive form).

- In turn, expanded competence of the Commission calls for a stronger oversight on the quality of the Commission IAs: this can be achieved in several ways, including strengthening the IAB, and enhancing/ institutionalising the role of existing networks such as the HLG of national

${ }^{21}$ The consultation document and opinions espressed can be found at http://ec.europa.eu/governance/better_regulation/smart_regulation/consultation_en.htm. 
regulatory experts and the HLG of independent stakeholders, but not by appointing a brand new independent agency.

- There is a need to effectively manage the resources available for the implementation of better regulation at EU level: especially if the Commission will have an expanded role in formulating and updating IAs throughout the policy cycle, then the need to focus on some key initiatives and strengthen the analysis of binding proposals rather than broader strategy documents becomes more compelling. This also includes a careful allocation of resources between ex ante impact assessment and ex post evaluation.

- Accordingly, there is a need for stronger targeting of IAs, control on the selection of proposals and decisions on proportionality (i.e. depth and scope of the analysis for each step of the process). This activity can be performed by the SecGen/IAB, but following more closely the indications that should be issued by the Council as regards the strategic priorities in the EU agenda every year. Proportionality of analysis should be decided by having regard to the whole policy cycle of the proposal at hand, also by deciding when the biggest IA effort should be placed.

- There is also a need to clarify the future role of the SCM and its relation to the IA system. Currently, many aspects of the Action Programme remain obscure: whether the SCM will be applied more broadly than IA; whether it will require systematic and capillary quantification of burdens for each binding proposal coming out of Brussels; whether it will be expanded to other compliance costs; whether the targets will be "net"; whether the baseline will be kept "live"; and whether the Commission will have to update each and every quantification of burdens as its proposals flow into the codecision procedure.

- Finally, multi-level convergence can be achieved by carefully implementing the Action Programme on administrative burdens, and using the SCM as a "shortcut" to achieve more convergent better regulation agendas in the years to come. In order to achieve this goal, however, more sophisticated safeguards have to be put in place to ensure coordination between the EU measurement and national ones - provided that they will effectively be launched by all member states and with sufficient rigour.

\subsection{The EU impact assessment system: lessons learned}

Several lessons can be drawn from the experience of the European Commission with IA procedures.

- First, the successful implementation of IA takes time. The European Commission has relatively quickly managed to introduce IA due to its previous experience with more partial assessments (such as the BIA, or the environmental impact assessments); due to pressure by Member States wishing to establish guarantees that the wave of structural reforms that was triggered by the Single Market plan in 1985-1992 would not result in badquality new legislation; due to the relatively sophisticated competences it 
hosts in its services compared to national public administrations in several EU member states; and due to the decision to strengthen the governance of the system by appointing the IAB.

- Second, the design of the system is essential for its success. The first years of implementation of the RIA system had led to some disappointment among commentators and stakeholders. Demand for quality assurance systems within the Commission led to the appointment of the IAB, which in turn generated significant pressure on DGs (see also below). The final word on this debate, in any event, has not been spelled: business stakeholders, in particular, would like to see the appointment of an independent body in charge of overseeing the Commission's activities. Even without embarking in a complex institutional puzzle - the creation of yet another EU agency there is significant consensus on the need to increase transparency by calling on the Commission to publish draft IAs for consultation before the IAB decides on their quality. Finally, several additional gatekeepers are entering the stage, from the European Parliament to the European Court of Auditors and the Stoiber group, all with the firm intention to have a stronger say on the development of the system in the years to come.

- Third, a RIA system becomes mature alongside with the sense of ownership of administrations. The fact that the several DGs have yet to be fully involved in the process (see Figure 3 above) reveals margin for improvement at the EU level. On the other hand, DGs such as MARKT and ENTR are working on their own, expanded version of the IA guidelines to make sure their officials produce better proposals and do not elicit negative comments by the IAB. This reveals the importance of oversight bodies at the centre of government, and the need for a fine-tuning of the IA methodology according to the sector in which IA is performed. 


\section{RIA IN EUROPEAN COUNTRIES: EMERGING TRENDS}

Compared to the progress achieved by the European Commission in ex ante impact assessment, most EU member states appear to significantly lag behind. While one country, the UK, clearly took the lead in Europe, significantly determining the launch of the IA system in Europe, to date in several Member States IA is still on paper, or has even not been launched. A snapshot of the current adoption-implementation gap is provided by the comparison of Figure 7 and Figure 8 below. In Figure 7, the results of the OECD "government at a glance" in 2009 are reported, with specific focus on explicit requirements for RIA processes in Central government. These variables describe the extent to which RIA is sponsored and formally adopted in central governmental structures.

Figure 7 - Requirements for RIA in central governments, with sensitivity analysis, 2005 v. 2008

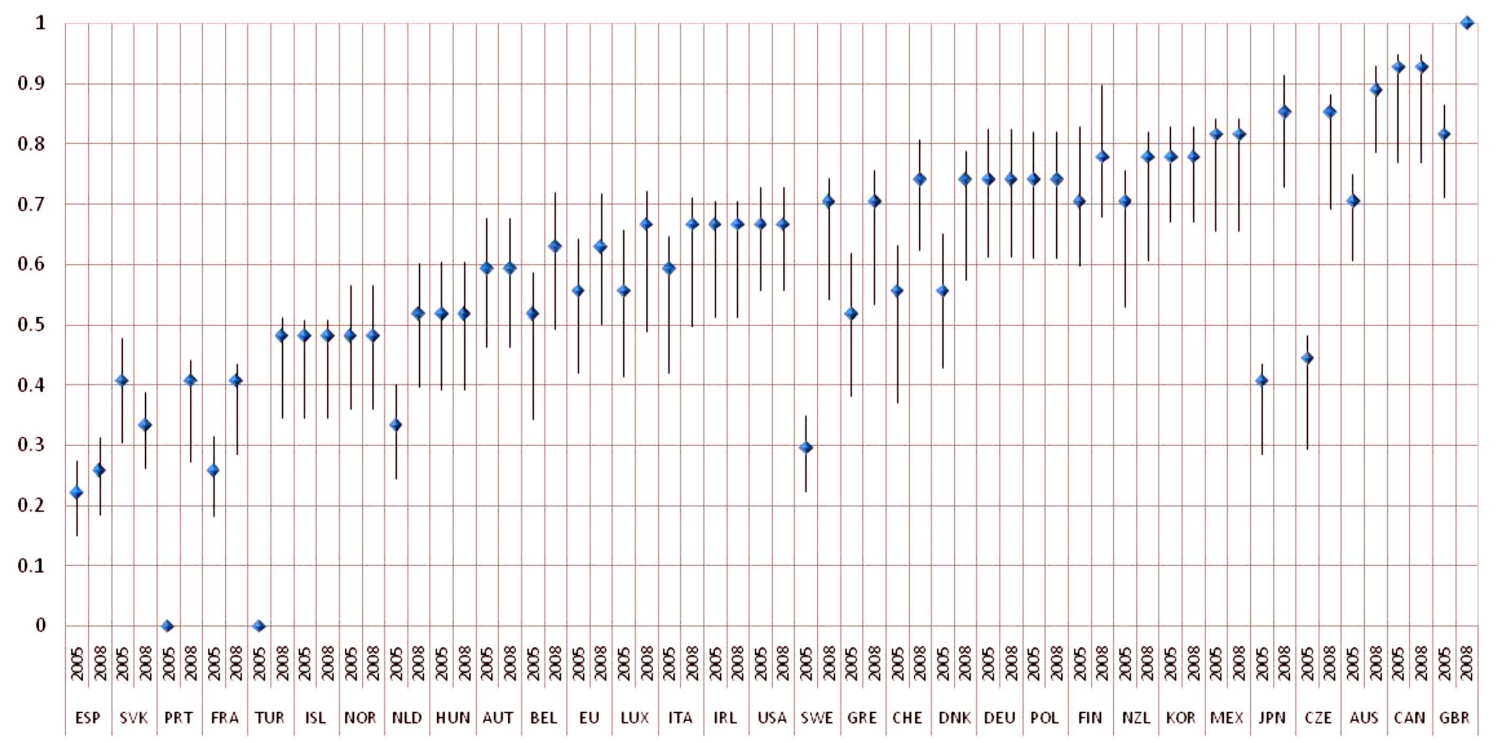

When looking at the actual implementation of RIA in practice, it is important to define RIA in the first place. The ENBR project back in 2005 hosted a discussion between experts on what can constitute a valid definition of RIA. According to ENBR experts, a RIA has four components (ENBR Handbook on Methodology 2006:6):

1) A systematic, mandatory, and consistent assessment of aspects of social, economic, or environmental impacts such as benefits and/or costs. This means that an IA is part of a system of impact analysis based on clear scope and directions. The scope can be narrow or broad, but it is clear that an IA is not an intermittent or voluntary effort to examine impacts. 
2) Affecting interests external to the government. The purpose of IA is to expand the range of impacts relevant to decisions to external impacts. An assessment only of fiscal or government budget implications is an input into traditional fiscal policy, and is not IA in the modern sense.

3) Of proposed regulations and other kinds of legal and policy instruments. Governments use many policy instruments to implement policy, and ex ante assessment of impacts can be used for most or all of those instruments.

4) To i) inform policy decisions before a regulation, legal instrument, or policy is adopted; or ii) assess external impacts of a group of laws or regulations to support reforms; or iii) assess the accuracy of an earlier IA.

This definition, in and of itself, led ENBR researchers to exclude many documents published by national governments, which appear to lack some of the typical features of a RIA. This already created concerns in the real nature of the documents being produced by national governments in Europe, which are termed as RIA, but in fact are something different from a systematic requirement to perform ex ante impact assessment of proposed legislation.

Figure 8 below shows the number of actual IA documents produced by governments that matched the ENBR definition illustrated above at the end of 2008, for each of the countries covered by the ENBR DIADEM database. As shown in the picture, only the UK, Ukraine and the European Commission could be said to have reached a sufficient level of RIA documents - with many differences - among the countries covered.

Figure 8 -Impact Assessments in the DIADEM database, end of 2008

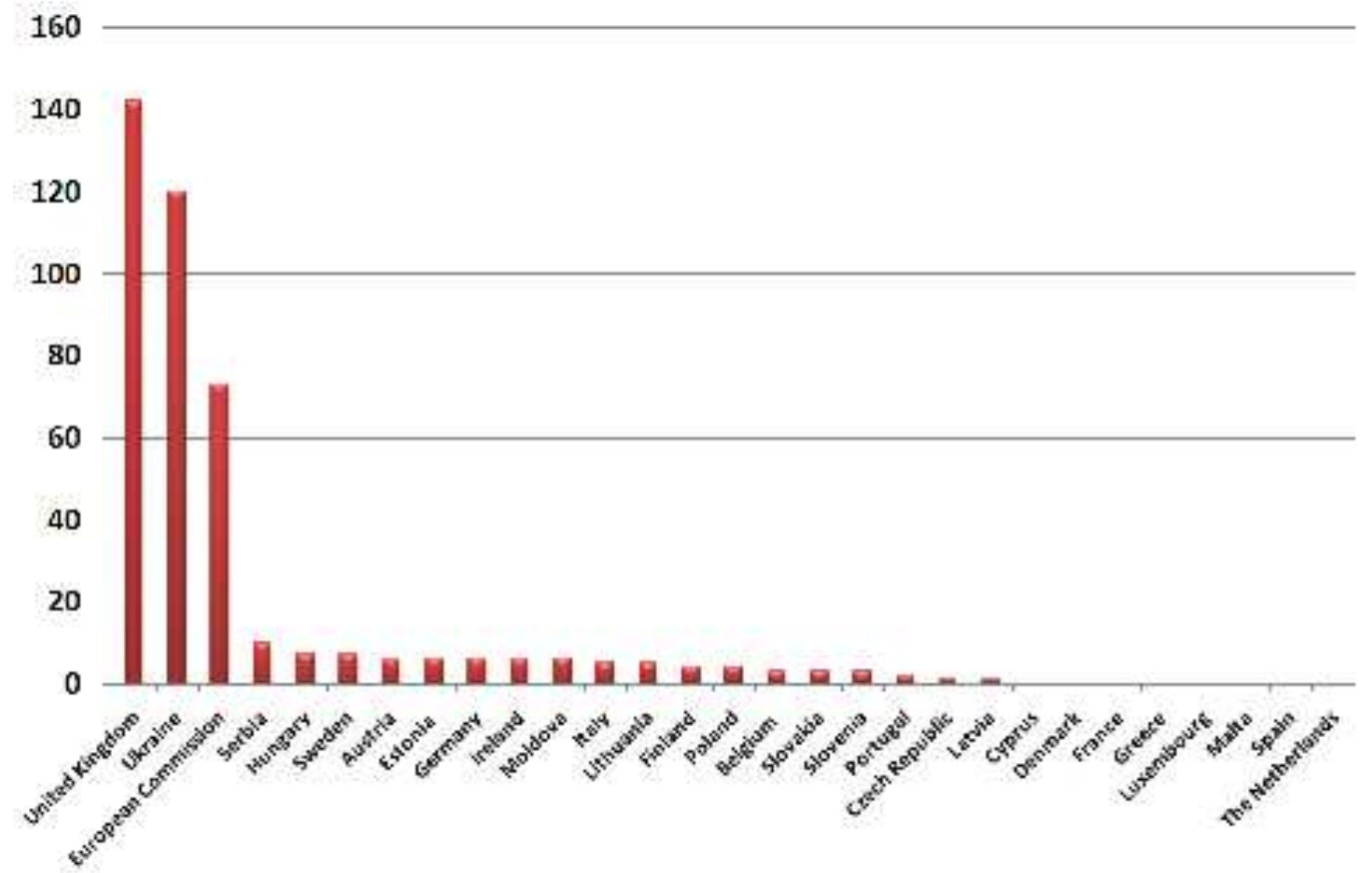

Source: DIADEM database, www.enbr.org 
Interesting and more updated results were found, for a more limited number of countries, by Staronova (2010) for the Central and Eastern European Countries, and by the OECD EU15 project. Overall, the review of better regulation in the 15 countries has revealed the existence of a number of problems in the implementation of ex ante impact assessment, including, most notably, the need to clarify the link between IA and administrative burden reduction programmes, which appear more widespread and more strongly implemented at national level. The reason for this may well be that the Standard Cost Model, on which burdens reduction programmes are based, is a less intrusive model as it does not require a real change in the culture of public administrations; and also because it is easier to communicate to stakeholders, as it leads to clearly identifiable reduction proposals. At the same time, however the SCM has a much narrower scope that ex ante IA, since it only looks at administrative burdens and can potentially extended to compliance costs, but does not look at the benefits of legislation in place or alternative policy options.

\subsection{Grouping EU countries}

Looking at the EU27 landscape, it is possible to distinguish different types of countries as regards their experience on IA procedures.

- Pioneers. As already explained, one country - the UK - can be defined as pioneer in Europe, having experimented with IA practices since the 1980 and with a more full-fledged IA since 1998. Other countries, i.e. Denmark, Germany, Hungary, the Netherlands, and Sweden have been defined as pioneering countries, since they formally adopted RIA before the OECD agreement on regulatory reform. However, in none of these countries RIA has been successfully implemented in the policy process.

- CEE countries. Finally, some Central and Eastern European countries - also pushed by the OECD Sigma project - have launched RIA pilots back in the 1990s. This is the case, in particular, of Hungary and Estonia, which started experimenting with RIA in 1994 and 1999, respectively (Staronova, 2010); in the Czech Republic, the Legislative Rules of Government introduced a RIA requirement in 1998 but it only entered into force in 2007. In Slovakia, requirements for RIA were introduced in November 2001 via an amendment of the Legislative Rules of the Government, following recommendations by the Audit of State Administration. In 2004, the Slovenian government signed The Act on Cooperation between the National Assembly and the Government in EU Affairs, which obliges the Government to carry out assessments of the impact and implications of draft EU-related measures. In Poland, already at the end of 2001 IA became compulsory for all the legislative drafts adopted by the Council of Ministers, and a Department for impact assessment was established at the Government Legislation Centre. Early starters have, however, faced several difficulties in effectively implementing RIA in their policy cycle. For example, Hungary, despite its early attempt in 1994, has never managed to produce good quality RIA documents over time, and reportedly lags behind other CEE countries in several respects, including consultation, the identification and analysis of 
impacts, and the overall quality of the assessment. Estonia, on the other hand, has gradually managed to improve the system and was later joined by the Czech Republic, where only a few, high quality RIAs have been produced to date ${ }^{22}$.

- Late adopters often have the advantage of learning from other countries' mistakes, and can achieve better outcomes within a lower time frame. A first consequence of this has been the emergence of a group of successful late adopters in the EU27. For example, Ireland has abandoned its fragmented system that entailed separate assessments of various impacts (including poverty impact assessment) to launch a more comprehensive RIA system in 2007. Similarly, the government of The Netherlands is considering the launch of a comprehensive RIA system that replaces the previous threepronged ex ante assessment model, based on business impacts, environmental impacts and the practicability and enforcement assessment in use since 1994. Sweden has made enormous progress in its adoption and implementation of RIA, and in December 2007, the Government issued a Regulatory Impact Assessment Ordinance, which supersedes the Ordinance on Special Impact Assessment of the Effects of Rules on Conditions for Small Enterprises, which previously regulated IA work. The new Ordinance states that IA must now be carried out for every new or amended regulation. The watchdog set up by the business confederation, the NNR, has observed that in the past eight years IA has progressed noticeably in Sweden, but also stated that too few good RIAs are being produced. Finally, after years in which the RIA system had faced significant adoption problems, let alone implementation, France has launched a new system of impact studies since 1 September 2009: the system possesses a unique feature in Europe, as impact studies have been made a constitutional requirement. Absent a (sufficiently detailed) RIA document attached to bills sent by the Government to parliament, the Speakers of either of the two assemblies may refuse to place the related policy item on the agenda, including if they find it inadequate.

- Countries dominated by the "cutting red tape" agenda. There is a clearly emerging group of countries where the better regulation rhetoric has evolved into a de-regulation and simplification one, leading to the blossoming of programmes to cut red tape, and to gradually shift the focus towards administrative burdens reduction, and away from more full-fledged RIA. These countries certainly include Germany, where the formal adoption of RIA - very much in line with the original OECD approach - never led to a real implementation of RIA in practice, while the Standard Cost Model has successfully permeated the regulatory agenda, and is currently being revised to cover, more generally, regulatory costs to businesses. Similar developments can be observed in Denmark, due to an early and very successful implementation of the SCM; in Finland and in Austria, where business associations and a fistful of courageous academics are trying to

22 Staronova, 2010. 
create momentum for RIA in an environment in which the dominant form of policymaking does not accommodate for real transparency 23 .

- Finally, a group of laggard countries seems to face important problems in mainstreaming RIA into their often complex policymaking process. Italy, for example, adopted the RIA procedure quite early (in 1999), but have never managed to really implement it to date, if not limited to one independent sectoral regulator and a fistful of regional governments - the regulatory framework to support RIA adoption in Central Government was completed only in the spring of 2009. On the other end of the spectrum, Greece decided to start experimenting with RIA in 2007, but launched an overly ambitious project, which ended up almost impossible to take up all at once. ${ }^{24}$ Finally, Bulgaria, Romania, Lithuania, Latvia, Spain and Portugal seem light years away from a successful implementation of RIA. Similar issues could be said about Luxembourg, Malta and Cyprus.

Table 1 below summarises my conclusions in terms of grouping of countries according to their RIA implementation. It bears observing, in this respect, that implementation should not be equated with success, but only with the achievement of a regular production of RIA documents as a mandatory requirement, supported by guidance on how to produce the analysis, and subject to scrutiny and internal or external quality control. Examples of countries that have adopted RIA but not implemented it are, unfortunately, abundant; in addition, countries that have indeed implemented RIA have sometimes failed, sometimes only partly succeeded: the example of the UK, where efforts to mainstream RIA in the policy process have led to overlapping generations of regulatory reforms, patchy and fragmented implementation, tendency towards box-ticking, limited quantification of impacts, and finally a remarkable shift towards the reduction of administrative burdens generated by the stock of legislation is not necessarily the most successful case study one can think of.

Table 1 - Groups of countries according to effective implementation of RIA

\begin{tabular}{|l|l|l|l|l|}
\hline \multicolumn{1}{|c}{ Pioneers } & \multicolumn{1}{c}{$\begin{array}{c}\text { CEE countries } \\
\text { with RIA } \\
\text { development }\end{array}$} & \multicolumn{2}{c|}{ Late adopters } & \multicolumn{1}{c|}{$\begin{array}{c}\text { Red-tape- } \\
\text { dominated }\end{array}$} \\
devaggards \\
United Kingdom & $\begin{array}{l}\text { Czech Republic, } \\
\text { Estonia, Hungary, } \\
\text { Poland, Slovakia, } \\
\text { Slovenia }\end{array}$ & $\begin{array}{l}\text { France, Ireland, } \\
\text { The Netherlands, } \\
\text { Sweden, Belgium } \\
\text { (Flanders) }\end{array}$ & $\begin{array}{l}\text { Austria, Belgium } \\
\text { (Central gov), } \\
\text { Denmark, Finland, } \\
\text { Germany }\end{array}$ & $\begin{array}{l}\text { Bulgaria, Greece, } \\
\text { Italy, Lithuania, } \\
\text { Latvia, } \\
\text { Luxembourg, } \\
\text { Malta, Portugal, } \\
\text { Romania, Spain } \\
\text { Cyprus }\end{array}$ \\
\hline
\end{tabular}

Source: Author's elaboration from several sources.

Notwithstanding the rather depressing picture that emerges from the current implementation of RIA in the EU27, several lessons can be drawn from the

23 Weigel (2008); and Biegelbauer and Meyer (2007, 2008).

24 Hatzis, A. (2006). 
experience of past research projects, direct field experience, academic literature and reports by international organisations such as the OECD and the World Bank. I try to briefly summarise them below.

- Political commitment remains essential. Typical examples are those of France and The Netherlands, where comprehensive RIA systems have been or are being launched as a result of a solid demand for regulatory governance and reform. Where commitment has been limited or absent (e.g. Italy, Poland, Germany), even the most ambitious RIA strategy has failed.

- Oversight and coordination. The invaluable role of central watchdogs has led several countries (but also the European Commission) to recognise the need for a centralised gatekeeper entrusted with the task of managing the RIA process and its development. Even where this has happened, the level of commitment and investment has markedly differed: Radaelli et al. (2007) reported that in four countries (Germany, Hungary, the Netherlands and Spain) the number of employees dedicated to RIA is unknown notwithstanding the presence of a central unit; whereas Ireland and Italy have very light central unit with 1.5 employees respectively. To the contrary, larger units exist in Czech Republic (9 employees), Poland (10), Sweden (12), and Belgium (20); whereas the UK stands as an outlier with approximately 70 employees.

- Hierarchy. Another important lesson that can be drawn is related to the relative positioning of the central coordinating body vis à vis administrations in charge of RIA. In countries where the oversight unit has been put at the same level of administrations in charge of producing RIAs, as unus inter pares, the moral suasion impact of its decisions has been limited 25 . To the contrary, where the watchdog acts from the centre of government, with a somewhat superior authority, there is often no need to grant the watchdog powers to formally reject proposal: as in the case of the US OIRA and the EU IAB, moral suasion is enough, no administration would dare to neglect the gentle advice of the watchdog.

- Expectations. Some national governments have made the mistake of launching an overly ambitious RIA system, and/or raised too high expectations among stakeholders. Examples, as already mentioned, include the European Commission (due to initial promises of full quantification), Italy, and Greece. Given that RIA takes several years to produce meaningful results, including i.a. enhanced predictability, transparency and accountability of policymaking, as well as greater policy coherence, it is important that reforms are communicated with a word of caution and by keeping in mind a reasonably long time horizon. Otherwise, the first episodes of disappointment among stakeholders may jeopardize the entire process.

- Gradual introduction v. big bang. Connected to the problem of expectations is the problem of how and when to introduce RIA. The experience of countries such as the UK, France and the Netherlands suggests that it may take several years before a system of partial, narrower-scope assessments

25 Staronova (2010) 
can generated momentum and demand for a more comprehensive RIA system. Also the European Commission has gone through years of separate assessments (the BIA, the environmental and sustainability impact assessments developed by different DGs) before moving to an integrated system: and yet it took several years before the Commission services got used and acquainted with the specifics and the technicalities of IA.

- Exploit the link with the SCM. Faced with problems in generating the cultural change needed in public administrations, several governments have opted for reforms related to simplification and the reduction fo administrative burdens. Given the political commitment required for the implementation of the SCM - i.e. the ex ante commitment to reduce burdens by a given percentage before actually measuring them - the SCM has proven easier to communicate to business stakeholders. At the same time, the SCM does not require revolutionary changes in the way bureaucrats behave, as most of the process is carried out in conjunction with external consultants and is aimed at the stock, rather than the flow of legislation. That said, once administrative burdens have been measured, reduction proposals must be assessed as regards their potential costs and benefits for society as a whole. As explained in Allio and Renda (2010), IA procedures are required to successfully complete the implementation of the SCM: accordingly, a new momentum for introducing a comprehensive IA system may emerge in all those countries - practically, all EU member states - that have decided to embark in the measurement of administrative burdens, especially after the Spring Council in 2007. 


\section{CONCLUSION}

A few years ago, it would have been difficult to predict that in 2010, the most (and perhaps the only) successful and established RIA system in Europe would become that of the European Commission. Indeed, an analysis of RIA practices in the EU27 reveals that impact assessment is navigating through rather difficult waters. The difficulty in spotting results, the impact of the financial crisis and the debate on stress-testing of legislation, the failure to account for enforcement and compliance and to merge RIA practice with insights from modern economics all contribute towards a re-consideration of RIA, despite recent attempts to re-launch the system in countries like the Netherlands, Sweden, France and Italy. In this quagmire, more practical models such as the SCM thrive, since they appear more down to earth, more handy for administrations, and overall more useful for businesses.

The rather discouraging landscape emerging from field work carried out by experts in projects such as ENBR and EVIA, but also clearly portrayed in recent OECD publications, calls for a moment of reflection. The EU and national experiences suggest that RIA takes time, that it must be carefully designed to activate the appropriate mechanisms (from learning to principal-agent mechanisms, which in turn depend on the principal scope of the RIA system), that it crucially depends on how expectations are managed during its implementation, and that political commitment remains essential in order to achieve a reasonably long and credible time frame for reform. In addition, recent developments highlight the importance of developing a network of gatekeepers, internal and external to the central government administration, able to act both ex ante (as in the case of oversight agencies and advisory bodies such as Actal and its homologous in other countries) and ex post (as in the case of courts of auditors in some EU countries and the EU.

The solution to the current impasse probably lies in a twofold strategy:

- First, efforts at the EU and national level should be merged into a comprehensive, multi-level strategy for the quality of lawmaking in the European Union: this could be achieved in particular by exploiting the momentum offered by the programmes enacted in all Member States to measure and reduce administrative burdens.

- Second, the precondition for making RIA a success is to "first, make it good": the methodological approach and the overall scope of the exercise have to be reconciled with sound economics.

In this latter respect, it is probably time to go back to the pioneering experience in RIA development, that of the US, to recall some of its main features that have been often neglected when implementing RIA in European countries.

First, in the US RIA remains mandatory only for secondary legislation, within a strong principal-agent chain that links government agencies to the President of the US, acting through the OIRA. Emphasis on quantification and calculation of net benefits is functional to the need of centre-of-government to control more 
specialized bureaucracies: despite some recent attempts in this direction, Congress and independent agencies have no mandatory RIA requirement.

Second, over the past few years the US witnessed an growing activity of gatekeepers such as the GAO and the Congressional Budget Office. For example, the GAO has recently been rather vocal in identifying gaps in the transparency of OIRA's involvement in rule making, raising concerns about the results of the cumulative procedural and analytical requirements placed on rule making over the years ${ }^{26}$; and advocating for more transparency at OIRA to better allow the public to understand the effects of OIRA's reviews. The GAO periodically reviews selected rules as regards the appraisal procedure that take place inside the agencies ${ }^{27}$. In addition, a degree of oversight on the RIA process is exerted by the $\mathrm{CBO}$ through expert reports that look at the activity of specific agencies, for example the EPA. More occasionally, the $\mathrm{CBO}$ also reviews the functioning of the RIA system in government agencies.

Third, the Obama administration has marked a change in the approach to RIA, thanks mostly to the appointment of Cass R. Sunstein as the new chairman of the OIRA. The new approach at OIRA is likely to devote more attention to behavioral law and economics and the analysis of individual incentives and consumer behaviour, something that is often difficult to reconcile with mere quantification of costs and benefits ${ }^{28}$. This development would in my opinion bring more substance to the current practice of RIA, offering a potential avenue to more sophisticated policy appraisal also in Europe. And it would put an end to the current schism between policy evaluation in academia and in real life: after all, back in 1998 Anthony Ogus observed that the emergence of regulatory appraisal in the UK was a "neglected opportunity" for law and economics, and that the use of regulatory appraisal in the US and in the UK had been insufficiently permeated by this discipline, especially for what concerned the understanding of the relationship between legal rules and human behaviour ${ }^{29}$. Problems, according to Ogus, would mostly relate to "the predicted levels of

26 See GAO-07-791, at http://www.gao.gov/new.items/do7791.pdf; and GAO-05-939T, at http://www.gao.gov/new.items/do5939t.pdf.

27 A recent GAO report issued in April 2009 reviews 139 major rules including 16 case-study rules, and finds that: (i) OIRA's reviews of agencies' draft rules often resulted in changes (of 12 case-study rules subject to OIRA review, 10 resulted in changes, about half of which included changes to the regulatory text); (ii) Agencies used various methods to document OIRA's reviews, which generally met disclosure requirements, but the transparency of this documentation could be improved; (iii) out of eight prior GAO recommendations to improve the transparency OIRA has implemented only one-to clarify information posted about meetings with outside parties regarding draft rules under OIRA review .

28 See, for an example, the first review letter sent by the OIRA under the Obama administration, to the National Highway Traffic Safety Administration (NHTSA) related to the new "Tire Fuel Efficiency Consumer Information Program", available online at http://www.reginfo.gov/public/postreview/Tire_Fuel_Efficiency_Consumer_Information_ Final_Rule.pdf. Cass Sunstein's idea of "libertarian paternalism" and "behavioural law and economics" is elaborated in several publications, including the recent book with Richard Thaler, Nudge: Improving Decisions about Health, Wealth, and Happiness, Yale University Press, 2008.

29 A. Ogus, Regulatory Appraisal: A Neglected Opportunity for Law and Economics, European Journal of Law and Economics, Volume 6, Number 1, July 1998 , pp. 53-68(16). 
compliance; the counterfactual (the state of the world absent the regulation); the types of standards involved in the proposed measure; possible alternative regulatory techniques; and consideration of indirect effects."

This is what occurs in many IAs around the world today. Perhaps the best way to re-launch RIA as a useful tool for ex ante policy assessment would be to start from achieving the methodological tools and sophistication that are needed to ensure that legislators can understand markets and individual incentives before enacting legislation. 


\section{SELECTED REFERENCES}

- Biegelbauer, P. and S. Mayer, (2007), RIA or no RIA: the Dialogue Between Policymakers and Stakeholders in the Regulatory Process in Austria, ENBR Working Paper No.10.

- Biegelbauer, P., and S. Mayer, (2008), Regulatory Impact Assessment in Austria: Promising Regulations, Disappointing Practices, in: Critical Policy Analysis 2(2), pp. 118-142.

- Cecot, C., R. W. Hahn, A. Renda, and L. Schrefler (2008), An Evaluation of the Quality of Impact Assessment in the European Union with Lessons for the US and the EU, Regulation \& Governance, Volume 2, Number 4, December 2008 , pp. 405-424(20).

- De Francesco, F. (2008), Prerequisites of adoption and patterns of diffusion: the Case of regulatory impact analysis in European Union and OECD member states, Paper presented at the 58th Political Studies Association Annual Conference Democracy, Governance and Conflict: Dilemmas of Theory and Practice, Panel on EU External Relations and Regional Development, 1-3 April, Swansea University.

- Garoupa, N. and G. Vasconcelos Vilaça, The Practice And Discourse of Legislative Evaluation in Portugal, ENBR working paper 12/2007.

- Harrington W. et al. (2009). Controversies surrounding Regulatory Impact Analysis, in Harrington et al. (eds.), Reforming Regulatory Impact Analysis, pp.10-20. Washington, DC: Resources for the Future.

- Jacob, K., et al. (2008). Improving the practice of impact assessment. Berlin, EVIA consortium Final Report.

- Lenschow, A., P. Graef, K. Kurze and K. Rottmann, Exploring the German RIA-Puzzle, ENBR Working Paper 20/2008.

- Marcos Fernandez, F., J. Santaló Mediavilla and A. Sanchez Graells, Decentralisation, Regulatory Burden And Economic Development In Spain, ENBR Working Paper 05/2007.

- Ogus, A. Regulatory Appraisal: A Neglected Opportunity for Law and Economics, European Journal of Law and Economics, Volume 6, Number 1, July 1998 , pp. 53-68(16).

- Radaelli, C. M. (2004). The diffusion of regulatory impact analysis: Bestpractice or lesson drawing? European Journal of Political Research, 43(5), 723-747.

- Radaelli, C. M. (2005). Diffusion without convergence: How political context shapes the adoption of regulatory impact assessment. Journal of European Public Policy, 12(5), 924-943.

- Radaelli, C. M. (2009). Desperately seeking regulatory impact assessments: Diary of a reflective researcher. Evaluation, 15(1), 31-48. 
- Radaelli, C.M. (2010) 'Rationality, power, management and symbols: Four images of regulatory impact assessment', Scandinavian Political Studies, 33(2) in press.

- Radaelli, C. M., \& De Francesco, F. (2007). Regulatory Quality in Europe: Concepts, Measures, and Policy Processes. Manchester: Manchester University Press.

- Radaelli, C.M. and A.C. Meuwese (2009). Better regulation in Europe: between management and regulation, Public Administration, 87(3): 639654.

- Radaelli, C.M. and A.C. Meuwese (2010). Hard questions, hard solutions. Proceduralisation through impact assessment in the European Union, West European Politics, 33(1): 136-153.

- Radaelli C. M. (2005) What does regulatory impact assessment mean in Europe? Washington DC: AEI-Brookings Joint Center for Regulatory Studies.

- Radaelli, C.M., F. De Francesco and V.E. Troeger (2008) 'The implementation of Regulatory Impact Assessment in Europe', Paper presented at the European Network for Better Regulation, Workshop on Regulatory Quality: Developing tools, approaches and sources for research on impact assessment, University of Exeter, Exeter 27 and 28 March

- Radaelli, C. M., L. Allio, A. Renda and L. Schrefler, How to Learn from International Experience: Impact Assessment in the Netherlands, Report for the Dutch Government, available online at http://77.245.92.62/bestanden/documenten-enpublicaties/kamerstukken/2010/o6/21/onderzoeksrapport-impactassessment-in-the-netherlands-doc-20652/onderzoeksrapport-impactassessment-in-the-netherlands-doc-20652.pdf.

- Renda, A. (2006), Impact Assessment in the EU: the state of the art and the art of the state, Centre for European Policy Studies.

- Renda, A. (2008a), Law and Economics in the RIA World (March 28, 2008). Available at SSRN: http://ssrn.com/abstract $=1291032$

- Renda, A. (2008b), Advancing the EU better regulation agenda: Selected Challenges for Europe, Paper presented at the Bertelsmann Foundation's High Level Colloquium on Better Regulation, Brussels, 10-11 September 2008. At http://papers.ssrn.com/sol3/papers.cfm?abstract_id=1291030

- Renda, A., S. Kurpas, P. M. Kaczyński, L. Montoya, and L. Schrefler (2009), Policy-Making in the EU: Achievements, Challenges and Proposals for Reform, Centre for European Policy Studies, 2009. Available at SSRN: http://ssrn.com/abstract $=1417390$

- Rogowski, W. and W. Szpringer, Methodological Problems Of The Polish System Of Regulation Impact Assessment, ENBR Working Paper 04/2007, at http://www.enbr.org/public/ENBR\%20WP\%20042007.pdf.

- Staronova, K. (2010), Regulatory Impact Assessment: Formal Institutionalization and Practice, Journal of Public Policy, 30, 1, 117-136. 
- Sunstein, Cass R. and Richard H. Thaler, Nudge: Improving Decisions about Health, Wealth, and Happiness, Yale University Press, 2008.

- The Evaluation Partnership-TEP. (2007). Evaluation of the European Commission Impact Assessment System. Available at: http://ec.europa.eu/governance/impact/key_docs/key_docs_en.htm.

- Weigel, Wolfgang (2008), The Standard Cost Model - A Critical Appraisal. 25th Annual Conference of the European Association of Law and Economics, 2008. Available at SSRN: http://ssrn.com/abstract=1295861. 